\title{
MicroRNA-98 reduces amyloid $\beta$-protein production and improves oxidative stress and mitochondrial dysfunction through the Notch signaling pathway via HEY2 in Alzheimer's disease mice
}

\author{
FANG-ZHOU CHEN ${ }^{1}$, YING ZHAO ${ }^{2}$ and HUI-ZHAO CHEN ${ }^{1}$ \\ Departments of ${ }^{1}$ Neurosurgery and ${ }^{2}$ Ophthalmology, Affiliated Hospital of Taishan Medical University, \\ Taian, Shandong 271000, P.R. China
}

Received May 23, 2018; Accepted September 28, 2018

DOI: 10.3892/ijmm.2018.3957

\begin{abstract}
Alzheimer's disease (AD) is a chronic neurodegenerative disease that often occurs at a slow pace yet deteriorates with time. MicroRNAs (miRs) have been demonstrated to offer novel therapeutic hope for disease treatment. The aim of the present study was to investigate the effect of miR-98 on amyloid $\beta(\mathrm{A} \beta)$-protein production, oxidative stress and mitochondrial dysfunction through the Notch signaling pathway by targeting hairy and enhancer of split (Hes)-related with YRPW motif protein 2 (HEY2) in mice with AD. A total of 70 Kunming mice were obtained and subjected to behavioral assessment. The levels of oxidative stress-related proteins glutathione peroxidase, reduced glutathione, superoxide dismutase, malondialdehyde, acetylcholinesterase and $\mathrm{Na}^{+}-\mathrm{K}^{+}$-ATP were measured. Morphological changes in brain tissue, HEY2-positivity levels, neuronal apoptotic index (AI) and neuron mitochondrial DNA (mtDNA) levels were also determined. Subsequently, the levels of miR-98 and the mRNA and protein levels of HEY2, Jagged1, Notch1, Hes1, Hes5, $\beta$-amyloid precursor protein, B-cell lymphoma 2 (Bcl-2) and $\mathrm{Bcl}-2$-associated $\mathrm{X}$ protein in tissues and hippocampal neurons were determined by reverse transcription-quantitative polymerase chain reaction and western blot analyses, respectively. Finally, hippocampal neuron viability and apoptosis were determined using an MTT assay and flow cytometry, respectively. The levels of miR-98-targeted HEY2 and miR-98 were low and the levels of HEY2 were high in the AD mice. The AD mice exhibited poorer learning and memory abilities, oxidative stress function, and morphological changes of pyramidal cells in the hippocampal CA1 region. Furthermore, the
\end{abstract}

Correspondence to: Dr Hui-Zhao Chen, Department of Neurosurgery, Affiliated Hospital of Taishan Medical University, 366 Taishan Street, Taian, Shandong 271000, P.R. China E-mail: 13953853389@163.com

Key words: microRNA-98, hairy and enhancer of split-related with YRPW motif protein 2, Notch signaling pathway, amyloid $\beta$-protein, oxidative stress, mitochondrial dysfunction, Alzheimer's disease
AD mice exhibited increased protein levels of HEY2 and AI in the CA1 region of brain tissues with reduced mtDNA levels and dysfunctional neuronal mitochondria. miR-98 suppressed hippocampal neuron apoptosis and promoted hippocampal neuron viability by inactivating the Notch signaling pathway via the inhibition of HEY2. In conclusion, the results demonstrated that miR-98 reduced the production of $A \beta$ and improved oxidative stress and mitochondrial dysfunction through activation of the Notch signaling pathway by binding to HEY2 in AD mice.

\section{Introduction}

Alzheimer's disease (AD), the most prevalent disease leading to progressive dementia, is characterized by degenerative alterations in various neurotransmitter systems, including the monoaminergic neural system, and changes in selected brain regions $(1,2)$. Clinically, it is characterized by the progressive loss of cognitive function and memory (3). Several risk factors, including metabolic diseases, cardiovascular diseases, brain insults, aging and genetic factors, have been identified, however, the etiology of AD remains to be fully elucidated (4). As the most general form of dementia, AD is a widely recognized public health crisis, accounting for $50-70 \%$ of dementia cases $(5,6)$. Therefore, it is necessary to have an increased understanding of $\mathrm{AD}$ in order to improve its diagnosis and treatment, and to accelerate the development of novel therapeutics to reduce dementia symptoms.

Amyloid $\beta$-protein $(A \beta)$ peptides are generated by the successive proteolysis of $\beta$-amyloid precursor protein (APP), a transmembrane glycoprotein $(7,8)$ which is cleaved initially by the APP cleaving enzyme 1 (BACE1) and subsequently by $\gamma$-secretase in the transmembrane domain (9). Aggregated $A \beta$ is pivotal in the pathogenesis of $\mathrm{AD}(10)$. Following penetrating of the neuronal membrane, $A \beta$ aggregates and destroys cell membranes, inducing memory deficits and neuronal loss (11). Oxidative stress refers to the cytopathologic consequences of a mismatch between the production of free radicals and the ability of cells to defend against them (12). A previous study suggested that oxidative stress may be critical in neuronal degeneration in diseases including AD (13). Muhammad et al compiled findings on the significance of reactive oxygen 
species (ROS) in the pathophysiology of AD (14). Mitochondria are one of major sources of ROS in cells, and dysfunction in mitochondrial respiration can increase the formation of ROS in mitochondria (15). The importance of mitochondria in regulating cell apoptosis has been well-documented (16). Progressive mitochondrial dysfunction contributes to neuronal degeneration in age-mediated disease (17). It is possible that a downward spiral may be important to the pathogenesis of $\mathrm{AD}$, including an interaction between oxidative stress and mitochondrial dysfunction, promoting the initiation or/and amplification of ROS $(18,19)$.

Notch signals are transferred among adjacent cells through Notch receptors and their ligands that regulate differentiation, proliferation and apoptosis in several cell types, including stem cells (20). Hairy and enhancer of split (Hes)-related with YRPW motif protein 2 (HEY2), a hairy-related transcription factor family of Notch-downstream transcriptional repressors, has indispensable and complementary functions for the development of blood vessels (21,22). MicroRNAs (miRs) are small non-coding RNAs that regulate protein output post-transcriptionally, and each biological process is associated with miRNA-dependent regulation (23). miR-98 inhibits angiogenesis by modulating the activities of endothelial cells involved in tubule formation, cell invasion and cell spreading (24). The present study aimed to investigate the effect of miR-98 on the production of $A \beta$, oxidative stress and mitochondrial dysfunction through the Notch signaling pathway by targeting HEY2 in AD mice, with the aim of providing a novel basis for targeted therapy of AD.

\section{Materials and methods}

Ethics statement. The protocols of the present study were approved by the Institutional Review Board of the Affiliated Hospital of Taishan Medical University (Taishan, China). All animal experiments were performed according to the Guide for the Care and Use of Laboratory Animal by International Committees.

Study subjects and AD model establishment. A total of 70 Kunming mice (aged 24-30 months old, weighing 20-25 g), comprising 35 males and 35 females were provided by the Institute of Laboratory Animal of Sichuan Academy of Medical Sciences (Jianyang, China). They were acclimatized for 1 week prior to the experiment and were reared in cages according to gender. With natural light, all mice had free access to water and food. The room temperature of the laboratory was $18-22^{\circ} \mathrm{C}$, with relative humidity $40-70 \%$ and noise $<50 \mathrm{db}$. The mice were randomly divided into the AD group and the normal group (35 mice per group; all female). The mice were weighed and anesthetized with $0.4 \%$ sodium pentobarbital $(40 \mathrm{mg} / \mathrm{kg})$. Following routine disinfection, scopolamine (3 mg/kg) (0.3 mg/ml; Xuzhou Lane Pharmaceutical Co., Ltd., Xuzhou, Jiangsu) was injected into the subcutaneous occipital region of the posterior brain every day for a consecutive 2-week period to establish the AD model. The normal group was administered with equal volumes of normal saline for 2 weeks. The initial criteria of successful AD establishment were as follows: Slow movement, reduced food intake, unresponsive to external stimuli, dry hair, limb paralysis, overbalancing, and spinning to the right during tail lift. Finally, 28 AD mice were successfully modeled.

Behavioral assessment. A step-down passive avoidance test was performed 3 days following successful AD establishment. The platform reaction box, $10 \times 10 \times 5 \mathrm{~cm}$, was provided by the Institute of Materia Medical, Chinese Academy of Medical Sciences (Beijing, China). The box was divided into two sections by a copper gate with continuous electrical stimulation $(36 \mathrm{~V})$ at the bottom of the box. As a safe area for the mice to avoid electric shock, a rubber pad of $4.5 \mathrm{~cm}$ inner diameter and height was placed on the right rear corner of each box. Prior to assessment, the mice were placed in the instrument for 3 min with $36 \mathrm{~V}$ alternating voltage at the bottom of the copper gate. The time taken to react to jump to the pad (reaction time) and the number of electric shocks they received within $5 \mathrm{~min}$ (error frequency) were recorded as learning achievements. After $24 \mathrm{~h}$, the animals were again placed into the instrument for $3 \mathrm{~min}$ and then set on the pad. The first time they jumped off the pad (latent period) and the number of electric shocks they received within 5 min (error frequency) were recorded as memory achievements.

Oxidative stress detection in the mouse hippocampus. Following the behavioral assessment, eight mice were randomly selected and immediately sacrificed. The brain tissues were removed for index determination. The mice were sacrificed by cervical dislocation, and the hippocampus was removed immediately into an ice bath. The brain tissues were washed with saline, dried with neutral filter paper and placed in a homogenizer. Subsequently, $10 \%$ tissue homogenates were made with $0.25 \mathrm{~mol} / 1$ sucrose and $0.01 \mathrm{~mol} / 1$ Tris buffer and were centrifuged $\left(4^{\circ} \mathrm{C}\right)$ for $30 \mathrm{~min}$ at $11,450 \mathrm{x} \mathrm{g}$. The supernatants were collected to determine the activity and level of various oxidative stress markers, including glutathione peroxidase (GSH-Px), reduced glutathione (GSH), superoxide dismutase (SOD), malondialdehyde (MDA), acetylcholinesterase $(\mathrm{AChE})$ and $\mathrm{Na}^{+}-\mathrm{K}^{+}$-ATP. Assay kits used included the GSH-Px assay kit (cat. no. QS1202, Beijing Solarbio Science and Technology Co., Ltd., Beijing, China), the GSH assay kit (cat. no. BC1170, Beijing Solarbio Science and Technology Co., Ltd.), the SOD assay kit (cat. no. BC0170, Beijing Solarbio Science and Technology Co., Ltd.), the MDA assay kit (cat. no. A003-1, Nanjing Jiancheng Institute of Biological Engineering, Nanjing, Jiangsu, China), the AChE assay kit (cat. no. BH4872, Shanghai Bo Yao Biotechnology Co., Ltd., Shanghai, China) and the $\mathrm{Na}^{+}-\mathrm{K}^{+}$-ATP activity assay kit (cat. no. QS1700, Beijing Solarbio Biotechnology Co., Ltd.). All assays were performed in strict accordance to the kit protocol.

Hematoxylin and eosin $(H \& E)$ staining. On the 16th day following AD establishment, 10 mice in each group were sacrificed. The hippocampal tissues were removed and fixed with $4 \%$ paraformaldehyde for $24 \mathrm{~h}$. Following dehydration with 80,90 and $100 \%$ ethanol and n-butanol, the hippocampus was waxed in a $60^{\circ} \mathrm{C}$ wax box and then embedded in paraffin. Tissue sections $(5-\mu \mathrm{m})$ were dried at $45^{\circ} \mathrm{C}$ and obtained from each paraffin block. The sections were heated at $60^{\circ} \mathrm{C}$ for $1 \mathrm{~h}$ and dewaxed with xylene. Following hydration, the sections were stained with H\&E (Beijing Solarbio Science and Technology 
Co., Ltd.), dehydrated with gradient ethanol, cleared with xylene and mounted with neutral gum. Morphological changes of neurons in the CA1 region of brain tissues in the two groups of mice were observed under an optical microscope (XP-330; Shanghai Bing Yu Optical Instrument Co., Ltd., Shanghai, China). The procedure was repeated three times.

Immunohistochemistry. The treated hippocampal tissues were collected for the experiment. The sections $(30 \mu \mathrm{m})$ were exposed to rabbit anti-mouse (HEY2) monoclonal antibody (10597-1-AP, 1:100; Wuhan Sanying Biotechnology Co. Ltd., Wuhan, Hubei, China) at $4^{\circ} \mathrm{C}$ overnight and were subsequently incubated with biotinylated goat-anti-rabbit immunoglobulin G horseradish peroxidase (IgG-HRP) secondary antibody (cat. no. SE134, Beijing Solarbio Science and Technology Co., Ltd.) at $37^{\circ} \mathrm{C}$ for $30 \mathrm{~min}$. The nuclei were counterstained with hematoxylin (cat. no. C0105, Beyotime Institute of Biotechnology, Shanghai, China) for $30 \mathrm{sec}$ and developed with diaminobenzidine (cat. no. P0202, Beyotime Institute of Biotechnology). The sections were then dehydrated to transparency with hydrochloric acid ethanol and mounted with gum. The immunohistochemical criteria were as follows: Positive expression indicated that percentage of positive cells reached $>10 \%$, with obvious brown or brownish yellow particles present in the cytoplasm. Five visual fields were randomly selected and observed under an optical microscope. The positive expression rate was determined as the ratio of the number of positive samples to the total number of samples. The assessment was repeated three times.

Terminal deoxynucleotidyl transferase dUTP nick end labeling (TUNEL) staining. The treated hippocampal tissues were obtained for the experiment. A TUNEL kit (cat. no. C1086, Beyotime Institute of Biotechnology) was used to measure apoptosis of the hippocampal neurons. The sections were treated with $3 \% \mathrm{H}_{2} \mathrm{O}_{2}$, dewaxed with xylene I and II for 10 min each, dehydrated in gradient ethanol at concentrations of $100,95,80$ and $70 \%$ for 2 min each, and soaked with $3 \% \mathrm{H}_{2} \mathrm{O}_{2}$ at room temperature for $10 \mathrm{~min}$. Following washing with PBS for $5 \mathrm{~min}, 50 \mu \mathrm{l}$ protease $\mathrm{K}$ solution $(20 \mu \mathrm{g} / \mathrm{ml}$; cat. no. P6556, Sigma-Aldrich; EMD Millipore, Billerica, MA, USA) was added. The sections were detached at $37^{\circ} \mathrm{C}$ for $10 \mathrm{~min}$ and washed with PBS twice (5 min per wash). According to the manufacturer's protocol, the sections were treated with $50 \mu 1$ TUNEL reaction liquid, incubated at $37^{\circ} \mathrm{C}$ for $45 \mathrm{~min}$ and washed with PBS twice ( 5 min per wash). Following the addition of $50 \mu 1$ transfer fluid, the sections were incubated at $37^{\circ} \mathrm{C}$ for $45 \mathrm{~min}$, washed with PBS twice (5 min each wash), and developed with $50 \mu \mathrm{l}$ substrate at $25^{\circ} \mathrm{C}$ for $10 \mathrm{~min}$. Following washing completely, the sections were mounted, observed under a microscope and analyzed. Views of the CA1 region of the hippocampus were observed and recorded under a 400X optical microscope. Positive apoptotic cells in the CA1 region were analyzed using an image analyzer (ImageJ, V1.8.0 National Institutes of Health, Bethesda, MD, USA) Positive nuclear labeling was brownish yellow and negative cell nuclei were light blue. A total of 10 fields were randomly selected. The ratio of the number of positive cells to the total number of cells was determined as the apoptotic index (AI).
RNA isolation and reverse transcription-polymerase chain reaction (RT-PCR) analysis for mitochondrial DNA (mtDNA). To determine the copy number of neuron mtDNA, RT-qPCR analysis was used to analyze the total DNA content of the mitochondria. On the 18th day following AD establishment, 10 mice from each group were sacrificed. The brain hippocampal tissues $(100 \mathrm{ml}$ were removed and treated with $1 \mathrm{~m}$; TRIzol (Invitrogen; Thermo Fisher Scientific, Inc., Waltham, MA, USA). The tissues were ground on ice, placed in $1.5 \mathrm{ml}$ Eppendorf (EP) tubes, mixed uniformly with $200 \mu \mathrm{l}$ chloroform, placed at room temperature for $5 \mathrm{~min}$, and centrifuged at $4^{\circ} \mathrm{C}$ for $15 \mathrm{~min}(25,764 \mathrm{x} \mathrm{g})$. Subsequently, $300 \mu 1$ of the upper aqueous phase was removed, placed into new centrifuge tubes, mixed uniformly with equal volumes of isopropyl alcohol, placed on ice for $10 \mathrm{~min}$ and centrifuged at $4^{\circ} \mathrm{C}$ for $10 \mathrm{~min}$ $(25,764 \mathrm{x} \mathrm{g})$. Following discarding of the supernatants, the tissues were treated with $1 \mathrm{ml}$ precooled $75 \%$ ethanol at $4^{\circ} \mathrm{C}$ and centrifuged at $4^{\circ} \mathrm{C}$ for $2 \mathrm{~min}(25,764 \mathrm{x} \mathrm{g})$. The supernatants were discarded again and the EP tubes were inverted and dried at room temperature. RNA was dissolved in $70 \mu \mathrm{l}$ diethyl phosphorocyanidate. The tissues were incubated in a water bath at $55^{\circ} \mathrm{C}$ for $15 \mathrm{~min}$ and stored at $-80^{\circ} \mathrm{C}$. cDNA was synthesized using a reverse transcription kit (cat. no. 10601ES76, Shanghai Yi Sheng Biotechnology Co., Ltd., Shanghai, China). The system was prepared in sterile EP tubes. The reagent $(20 \mu \mathrm{l})$ was added according to the manufacturer's protocol, and the synthesized cDNA was stored at $4^{\circ} \mathrm{C}$. The copy number of the mitochondrial coding gene COXI was used as the $m t D N A$ copy number, and 8-Oxoguanine DNA-glycosylase 1 (Ogg1) was used as an internal reference for the purpose of reducing the difference in the amount of DNA template in different tissues. According to gene sequences in the GenBank database (www.ncbi.nlm.nih.gov/genbank) mitochondrial primers were designed and synthesized by Shanghai Sangon Biotech Co., Ltd. (Shanghai, China). The PCR sample and protocol were as follows: 2X $10 \mu \mathrm{l}$ TaqMan Universal PCR Master Mix, $0.4 \mu \mathrm{l}$ MT upstream and downstream primers, $0.4 \mu \mathrm{l} \mathrm{Ogg1}$

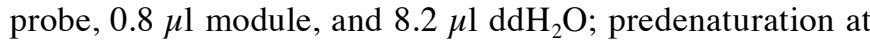
$95^{\circ} \mathrm{C}$ for $10 \mathrm{~min}, 40$ cycles of denaturation at $95^{\circ} \mathrm{C}$ for $15 \mathrm{sec}$, and annealing and extension at $60^{\circ} \mathrm{C}$ for $60 \mathrm{sec}$ (Table I). The gene amplification products of total mitochondrial RNA were assessed by $1 \%$ agarose gel electrophoresis. The average density value of each amplification product strip was analyzed by a gel image automatic analysis software Quantity One 4.4.0 (Bio-Rad Laboratories, Inc., Hercules, CA, USA). The relative density value of amplification products of mitochondrial genes and Ogg1 represented relative levels of mitochondria.

$R T$-quantitative PCR analysis (RT-qPCR) of $m R N A$ levels. The hippocampal tissues were removed, treated with $1 \mathrm{ml}$ TRIzol reagent (Invitrogen; Thermo Fisher Scientific, Inc.) and pulverized in an ice bath. According to the manufacturer's protocol of the TRIzol reagent, the total RNA of the tissues was collected. The purity and concentration of the RNA were detected by ultraviolet spectrophotometry (UV1901; Shanghai Austrian Scientific Instruments Co., Ltd., Shanghai, China). Samples with A260/A280=1.8-2.0 concentration were adjusted to $50 \mathrm{ng} / \mu \mathrm{l}$. The RNA was reverse transcribed into cDNA $(50 \mathrm{ng} / \mu \mathrm{l})$ with a PrimeScriptä RT reagent kit (cat. no. RR047A, Beijing, Zhi Jie Fang Yuan Technology Co., Ltd., 
Table I. Primer sequences for reverse transcription-polymerase chain reaction analysis.

\begin{tabular}{ll}
\hline Gene & \multicolumn{1}{c}{ Sequence } \\
\hline MT & F: 5'-CCCAGCTACTACCATCATTCAAGT-3' \\
& R: 5'-GATGGTTTGGGAGATTGGTTGATGT-3' \\
Ogg1 & F: 5'-ATGAGGACCAAGCTAGGTGAC-3' \\
& R: 5'-GCCTCACAATCAACTTATCCC-3'
\end{tabular}

MT, mitochondria; Ogg1, 7,8-dihydro-8-oxoguanine-DNA glycosylase; F, forward; $\mathrm{R}$, reverse.

Beijing, China) and stored at $-80^{\circ} \mathrm{C}$ until further use. The primers were automatically designed using gene tool software [GeneTool Lite V1.0, Genebio Bioinformatics (Genebio) SA, Geneva, Switzerland] and synthesized by Beijing TSINGKE Biological Technology Co., Ltd. (Beijing, China), listed in Table II. According to a two-step method, the experiment was performed with an ABI 7900HT real-time quantitative PCR instrument, with U6 and glyceraldehyde-3-phosphate dehydrogenase (GAPDH) as internal references. The reaction conditions were as follows: Predenaturation at $95^{\circ} \mathrm{C}$ for $30 \mathrm{sec}$, 40 cycles of denaturation at $95^{\circ} \mathrm{C}$ for $5 \mathrm{sec}$, annealing at $58^{\circ} \mathrm{C}$ for $30 \mathrm{sec}$ and extension at $72^{\circ} \mathrm{C}$ for $15 \mathrm{sec}$. The relative mRNA levels of miR-98, HEY2, Jagged1, Notch1, Hes1, Hes5, APP, Bax and Bcl-2 were calculated using the $2^{-\Delta \Delta \mathrm{Cq}}$ method (25). Three wells were included for each gene of each sample. This method was also used for subsequent cell experiments. The experiment was repeated three times.

Western blot analysis. The hippocampal tissues were removed. Following processing with liquid nitrogen, the tissues were ground into a uniform fine powder with a grinder (M20; Shanghai Shengke Instrument Equipment Co., Ltd., Shanghai, China) at low temperature, washed with PBS three times, added to protein lysate, and centrifuged at $4^{\circ} \mathrm{C}$ for $20 \mathrm{~min}$ $(25,764 \mathrm{x} \mathrm{g})$. The supernatants were collected and total protein concentration was determined using a bicinchoninic acid kit (cat. no. P0012-1, Beyotime Institute of Biotechnology). Cells in logarithmic growth phase were collected and centrifuged at $4^{\circ} \mathrm{C}$ for $20 \mathrm{~min}(1,610 \mathrm{x} \mathrm{g})$. Following discarding of the supernatants, the packed cell volume (PCV) was estimated, and every $20 \mu \mathrm{l} \mathrm{PCV}$ was mixed with $100 \mu 1$ lysate and $1 \mu \mathrm{l}$ phosphatase inhibitor (cat. no. 1111111, Beijing Jiamei Niono Biotechnology Co., Ltd., Beijing, China). The cells were then lysed on ice for $30 \mathrm{~min}$ and centrifuged at $4^{\circ} \mathrm{C}$ for $10 \mathrm{~min}$ at $25,764 \mathrm{x}$ g. The supernatants were collected for quantitative protein detection. Subsequently, $50 \mu \mathrm{g}$ protein was dissolved by $2 \mathrm{X}$ sodium dodecyl sulfate (SDS) sample buffer. Following boiling at $100^{\circ} \mathrm{C}$ for $5 \mathrm{~min}$, the samples were separated by $10 \%$ SDS-polyacrylamide gel electrophoresis, transferred onto polyvinylidene fluoride membranes, blocked with $5 \%$ skim milk at room temperature for $1 \mathrm{~h}$ and washed with PBS for 2 min. The PVDF membranes were then incubated with diluted rabbit-anti-mouse primary antibodies, including HEY2 (1:1,000, cat. no. ab86010), Jagged1 (1:500, cat. no. ab7771), Notch1 (1:500, cat. no. ab8925), Hes1 (1:200, cat.
Table II. Primer sequences used for reverse transcription-quantitative polymerase chain reaction analysis.

\begin{tabular}{|c|c|}
\hline Gene & Sequence \\
\hline miR-98 & $\begin{array}{l}\text { F: 5'-TGAGGTAGTAAGTTGTAT-3' } \\
\text { R: 5'-AACATGTACAGTCCATGATG-3' }\end{array}$ \\
\hline HEY2 & $\begin{array}{l}\text { F: 5'-CGCCCTTGTGAGGAAACGA-3' } \\
\text { R: 5'-CCCAGGGTAATTGTTCTCGCT-3' }\end{array}$ \\
\hline Jagged1 & $\begin{array}{l}\text { F: 5'-AGAAGTCAGAGTTCAGAGGCGTCC-3' } \\
\text { R: 5'-AGTAGAAGGCTGTCACCAAGCAAC-3' }\end{array}$ \\
\hline Notch1 & $\begin{array}{l}\text { F: 5'-GATGGCCTCAATGGGTACAAG-3' } \\
\text { R: 5'-TCGTTGTTGTTGATGTCACAGT-3' }\end{array}$ \\
\hline Hes 1 & $\begin{array}{l}\text { F: 5'-TCAACACGACACCGGACAAAC-3' } \\
\text { R: 5'-ATGCCGGGAGCTATCTTTCTT-3' }\end{array}$ \\
\hline Hes5 & $\begin{array}{l}\text { F: 5'-AGTCCCAAGGAGAAAAACCGA-3' } \\
\text { R: 5'-GCTGTGTTTCAGGTAGCTGAC-3' }\end{array}$ \\
\hline APP & $\begin{array}{l}\text { F: 5'-GTGGACTCTGTGCCAGCCAATA-3' } \\
\text { R: 5'-GTCTTGATGTTTGTCAGCCCAGAA-3' }\end{array}$ \\
\hline Bax & $\begin{array}{l}\text { F: 5'-AGACAGGGGCCTTTTTGCTAC-3' } \\
\text { R: 5'-AATTCGCCGGAGACACTCG-3' }\end{array}$ \\
\hline $\mathrm{Bcl}-2$ & $\begin{array}{l}\text { F: 5'-GAGGAGCTCTTCAGGGACGG-3' } \\
\text { R: 5'-GGTGCCGGTGCAGGTACTCA-3' }\end{array}$ \\
\hline GAPDH & $\begin{array}{l}\text { F: 5'-AATGGATTTGGACGCATTGGT-3' } \\
\text { R: 5'-TTTGCACTGGTACGTGTTGAT-3' }\end{array}$ \\
\hline U6 & $\begin{array}{l}\text { F: CTCGCTTCGGCAGCACA } \\
\text { R: AACGCTTCACGAATTTGCGT }\end{array}$ \\
\hline
\end{tabular}

miR-98, microRNA-98; HEY2, hairy and enhancer of split-related with YRPW motif protein 2; Hes1, hairy and enhancer of split 1; Hes5, hairy and enhancer of split 5; APP, amyloid precursor protein; Bcl-2, B cell lymphoma 2; BAX, Bcl-2-associated X protein; GAPDH, glyceraldehyde-3-phosphate dehydrogenase; F, forward; R, reverse.

no. ab71559), Hes5 (1:1,000, cat. no. ab194111), APP (1:500, cat. no. ab59592), Bax (1:1,000, cat. no. ab32503) and Bcl-2 (1:1,000, cat. no. ab119506). These antibodies were purchased from Abcam (Cambridge, MA, USA). The membranes were then washed with Tris-buffered saline Tween-20 (TBST) three times, and were incubated with secondary antibody goat-anti-rabbit labeled with HRP $(1: 5,000)$ for $1 \mathrm{~h}$. The membranes were washed with TBST three times ( 5 min per wash), developed with an enhanced chemiluminescence kit (cat. no. 10001, Beijing Branch Deep Blue Technology Co., Ltd., Beijing, China), exposed to X-rays and images were captured. The absorbance of colored bands was analyzed using the GelDoc, XR+ gel imaging analysis system [Bole Life Medicine Products (Shanghai) Co., Ltd., Shanghai, China]. The relative levels of sample protein equaled the average absorbance of samples to the average absorbance of relative internal controls. The relative levels of protein in each sample were used to plot a chart for statistical analysis. The experiment was repeated three times.

Cell culture, grouping and transfection. The hippocampal tissues were removed, and bilateral hippocampal tissues were 
Table III. Differences in learning and memory abilities between normal mice and AD mice.

\begin{tabular}{lccccc}
\hline \multirow{2}{*}{ Group } & \multicolumn{2}{c}{ Learning ability } & & \multicolumn{2}{c}{ Memory ability } \\
\cline { 2 - 3 } \cline { 5 - 6 } & Reaction time (sec) & Error time (sec) & & Reaction time (sec) & Error time (sec) \\
\hline Control (n=35) & $15.26 \pm 2.23$ & $2.18 \pm 0.25$ & & $195.88 \pm 18.06$ & $2.35 \pm 0.45$ \\
AD model (n=28) & $53.29 \pm 6.34^{\mathrm{a}}$ & $7.86 \pm 1.52^{\mathrm{a}}$ & & $75.14 \pm 5.47^{\mathrm{a}}$ & $8.17 \pm 0.47^{\mathrm{a}}$ \\
\hline
\end{tabular}

${ }^{\text {a }} \mathrm{P}<0.05$, compared with the control group. $\mathrm{AD}$, Alzheimer's disease.

Table IV. Indices for oxidative stress function between the normal and AD mice.

\begin{tabular}{llccccc}
\hline Group & $\begin{array}{c}\text { GSH-Px } \\
(\mathrm{U} / \mathrm{mg} \text { *pro })\end{array}$ & $\begin{array}{c}\text { GSH } \\
(\mathrm{mg} / \mathrm{g} * \text { pro })\end{array}$ & $\begin{array}{c}\mathrm{SOD} \\
(\mathrm{NU} / \mathrm{mg} \text { *pro })\end{array}$ & $\begin{array}{c}\mathrm{MDA} \\
(\mathrm{mmol} / \mathrm{mg} \text { *pro })\end{array}$ & $\begin{array}{c}\mathrm{AChE} \\
(\mathrm{U} / \mathrm{mg} \text { *pro })\end{array}$ & $\begin{array}{c}\mathrm{Na}^{+}-\mathrm{K}^{+}-\mathrm{ATP} \\
\left(\mathrm{U} / \mathrm{mg}^{*} \text { pro }\right)\end{array}$ \\
\hline Control (n 8) & $43.54 \pm 3.51$ & $1.06 \pm 0.18$ & $110.34 \pm 4.21$ & $5.27 \pm 0.44$ & $0.75 \pm 0.07$ & $31.45 \pm 1.95$ \\
AD model $(\mathrm{n}=8)$ & $31.51 \pm 2.92^{\mathrm{a}}$ & $0.66 \pm 0.12^{\mathrm{a}}$ & $123.25 \pm 9.61^{\mathrm{a}}$ & $3.75 \pm 0.38^{\mathrm{a}}$ & $1.65 \pm 0.11^{\mathrm{a}}$ & $21.51 \pm 1.21^{\mathrm{a}}$
\end{tabular}

${ }^{a} \mathrm{P}<0.05$, compared with the normal mice. GSH-Px, glutathione peroxidase; GSH, glutathione; SOD, superoxide dismutase; MDA, malondialdehyde; AChE, acetylcholinesterase; AD, Alzheimer's disease; pro, protein.

separated, and vessels and meninges were removed. Following washing with culture medium three times, the hippocampal tissues were placed in vials and cut into sections using ophthalmic scissors. Following the addition of $0.25 \%$ preheated trypsin at $55^{\circ} \mathrm{C}$, the hippocampal tissues were detached at $37^{\circ} \mathrm{C}$ for $30 \mathrm{~min}$ and filtered through a 500-mesh copper screen. The hippocampal neuron cell solutions of mice in the two groups were placed into $5 \mathrm{ml}$ tubes and centrifuged $\left(4^{\circ} \mathrm{C}\right)$ for $5 \mathrm{~min}$ at $402 \mathrm{x}$ g. Following discarding of the supernatants, the cells were resuspeded with $5 \mathrm{ml}$ complete-cultured cell suspensions by percussion, containing DMEM/F12 culture medium (1:1) with $20 \%$ fetal bovine serum (FBS; cat. no. 001001, Guangzhou Ruite Biotechnology Co., Ltd., Guangzhou, China), 40\% glucose DMEM (cat. no. SH30022.01, Guangzhou Zhanchen Biotechnology Co., Ltd., Guangzhou, China), and 40\% F12 medium (cat. no. GNM 11039, Hangzhou Dutai Biotechnology Co., Ltd., Hangzhou, China). The concentration of the cells was adjusted to $10^{9}$ cells $/ 1$. The cells were inoculated into 24-well cell culture plates at $37^{\circ} \mathrm{C}$ with $5 \% \mathrm{CO}_{2}(1 \mathrm{ml} /$ well). After $48 \mathrm{~h}$, the culture medium was replaced with a low-serum medium with $10 \mu \mathrm{mol} / 1$ cytarabine (Yixin Pharmaceutical Co., Ltd., Jilin, China). After $24 \mathrm{~h}$, the medium was replaced with DMEM/F12 feeding medium with $15 \%$ serum. The medium was replaced every 3.5 days. The culture continued for 9 days, following which the subsequent experiments were performed.

Hippocampal neuronal cells in the logarithmic growth phase were collected and divided into the normal group (hippocampal neurons of normal mice), the blank group (non-transfected hippocampal neurons of AD mice), the negative control (NC) group (hippocampal neurons of AD mice transfected with nonsense sequences), the miR-98 mimic group (hippocampal neurons of AD mice transfected with miR-98 mimic), the miR-98 inhibitor group (hippocampal neurons of AD mice transfected with miR-98 inhibitor), the small interfering (si)RNA-HEY2 group (hippocampal neurons of AD mice transfected with siRNA-HEY2), and the miR-98 inhibitor + siRNA-HEY2 group (hippocampal neurons of AD mice transfected with miR-98 inhibitor and siRNA-HEY2). The sequences were as follows: miR-98 mimic, sense 5'-UGA GGUAGUAAGUUGUAUUGUU-3', antisense 5'-CAAUAC AACUUACUACCUCAUU-3', miR-98 inhibitor: 5'-AACAAU ACAACUUACUACCUCA-3'; siRNA-HEY2, sense 5'-GCA CUGGGACAAACAAUAATT-3', antisense, 5'-UUAUUG UUUGUCCCAGUGCTT-3'; NC, sense 5'-UUCUCCGAA CGUGUCACGUTT-3' and antisense, 5'-ACGUGACACGUU CGGAGAATT-3'. Prior to transfection, cells in the logarithmic growth phase were inoculated into 6-well plates until the cells reached $80-90 \%$ confluence. Subsequently, the cells were transferred to serum-free culture medium Opti-DMEM (Gibco; Thermo Fisher Scientific, Inc.) and transfected using Lipofectamine 2000 in accordance with the manufacturer's protocol (Invitrogen; Thermo Fisher Scientific, Inc.). A total of $250 \mu \mathrm{l}$ lipo solution (cat. no. 11668-027, Shanghai Kanwin Biotechnology Co., Ltd., Shanghai, China) containing $240 \mu \mathrm{l}$ serum-free culture medium and $10 \mu \mathrm{l}$ lipo, was incubated for $5 \mathrm{~min}$ at room temperature. A total of $250 \mu \mathrm{l}$ plasmid solution was used, comprising $200 \mu \mathrm{l}$ serum-free culture medium and $50 \mu \mathrm{g}$ plasmid. The lipo and plasmid solutions were mixed and placed at room temperature for $20 \mathrm{~min}$. The mixed solution was added into the wells in a dropwise manner. The wells were mixed and incubated in $5 \% \mathrm{CO}_{2}$ at $37^{\circ} \mathrm{C}$. After 5-6 h, they were cultured in complete medium for $24-48 \mathrm{~h}$ to perform the subsequent experiments.

Dual-luciferase reporter gene assay. Target gene analysis of miR-98 was predicted using a biological prediction website (http://www.microRNA.org). A dual-luciferase reporter gene assay was used to validate whether HEY2 was a direct target gene of miR-98. The reporter vector pMIR-reporter (Promega Corporation, Madison, WI, USA) was inoculated in a 24-well 

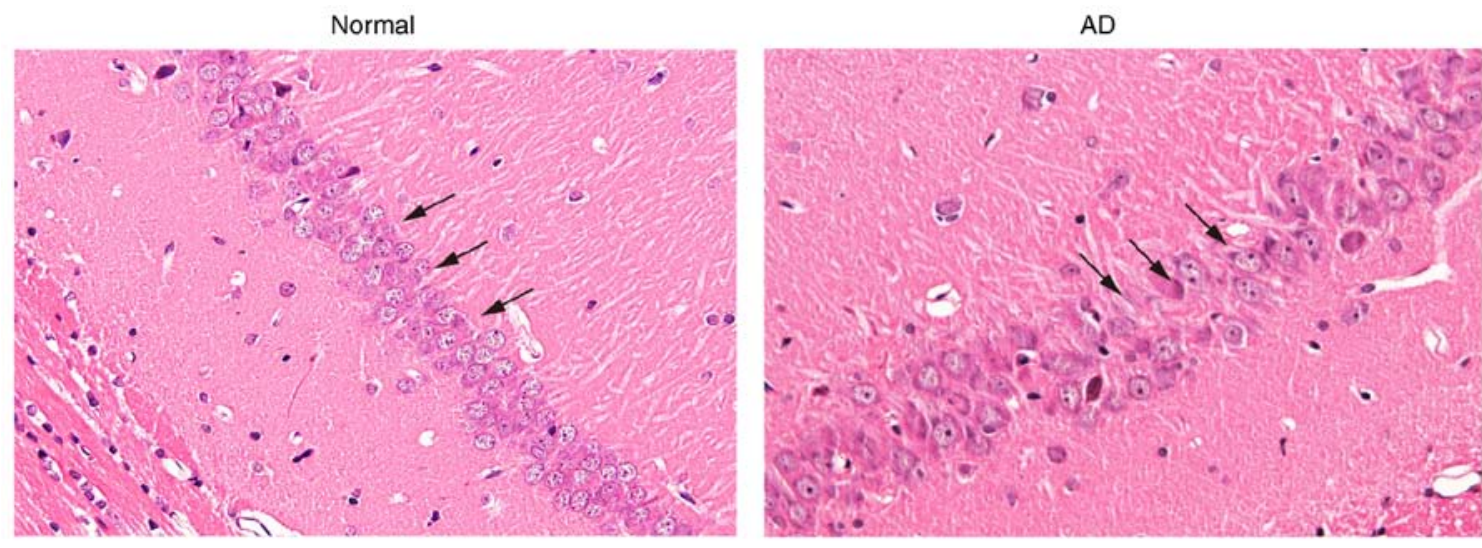

Figure 1. Hematoxylin and eosin staining results show that pyramidal cells in the hippocampal CA1 region exhibit more severe morphological changes. The black arrows indicate pyramidal cells in the hippocampal CA1 region, with differences between the normal group and the AD group. The original magnification is $\mathrm{x} 200$. AD, Alzheimer's disease.

plate and incubated for $24 \mathrm{~h}$. The HEY2 3'UTR gene fragment was artificially synthesized and was introduced into the pMIR-reporter (Promega Corporation) using endonuclease sites SpeI and HindIII. The mutant site sequences were designed in HEY2 wild-type (WT). Following undergoing restriction enzyme digestion, the target fragment was inserted into the pMIR-reporter plasmid through T4 DNA ligase, obtaining pHEY2-Wt. The binding site of the miR-98 and target gene was predicted using bioinformatics analysis for site-directed mutagenesis and the pHEY2-Mut vector was constructed. The pRL-TK vector (cat. no. E2241, Promega Corporation) of renilla luciferase-expressed enzyme was used as an internal reference to adjust for the variations in transfection efficiency and cell number. The miR-98 mimic and its negative control were cotransfected with the luciferase reporter vector into 293T cells (American Type Culture Collection). After $48 \mathrm{~h}$, the culture medium was removed and the cells were washed twice with PBS. The cells were split and the total proteins were collected. Luciferase activity was detected using a Dual-Luciferase ${ }^{\circledR}$ Reporter Assay System (cat. no. E1910, Promega Corporation). Every $10-\mu 1$ cell sample was treated with $50 \mu 1$ firefly luciferase working solution to measure firefly luciferase activity and with $50 \mu \mathrm{l}$ renilla luciferase working solution to determine renilla luciferase activity. The ratio of firefly luciferase activity to renilla luciferase activity was determined as the relative luciferase activity. The experiment was repeated three times.

MTT assay. Following transfection for $48 \mathrm{~h}$, cells in the logarithmic growth phase in each group were collected and cell suspensions $\left(1 \times 10^{4}\right.$ cells $\left./ \mathrm{ml}\right)$ were prepared in serum-free Opti-DMEM culture medium. The cells were inoculated in 96-well culture plates ( $\mathrm{n}=8$ wells per group, $100 \mu \mathrm{l}$ per well) and incubated at $37^{\circ} \mathrm{C}$ with $5 \% \mathrm{CO}_{2}$. The plates were removed following 24, 48 and $72 \mathrm{~h}$ of incubation. Each well was then treated with $10 \mu \mathrm{l}$ MTT solution $(5 \mathrm{mg} / \mathrm{ml}$, Sigma-Aldrich; EMD Millipore), and the cells were incubated for another $4 \mathrm{~h}$. Following incubation, the supernatants were discarded. Each well was treated with $150 \mu$ l dimethylsulfoxide and oscillated for $10 \mathrm{~min}$ to dissolve completely. The optical density (OD) value of each well was determined by an automatic enzyme reading meter (Bio-Rad Laboratories, Inc., Hercules, CA, USA) at the wavelength of $490 \mathrm{~nm}$.

Flow cytometry. At $48 \mathrm{~h}$ post-transfection, the cells were detached using trypsin without ethylenediaminetetraacetic acid, collected, centrifuged at $4^{\circ} \mathrm{C}(5 \mathrm{~min}, 178 \mathrm{x} \mathrm{g})$, and the supernatants were discarded. The cells were washed with precooled PBS, centrifuged at $4^{\circ} \mathrm{C}, 178 \times \mathrm{g}$ for $5 \mathrm{~min}$ and the supernatants were discarded again. Apoptosis was detected using an Annexin-V-FITC/PI Apoptosis Detection kit (cat. no. CA1020, Beijing Solarbio Science and Technology Co., Ltd.). The cells were washed with binding buffer. The mixed solution of Annexin-V-FITC and binding buffer was prepared at a proportion of 1:40. The cells were then resuspended, mixed uniformly by oscillation, and incubated at room temperature for $30 \mathrm{~min}$. Following the addition of the prepared mixed solution of PI and binding buffer, the cells were mixed uniformly by oscillation and were incubated at room temperature for $15 \mathrm{~min}$. Apoptosis was measured by flow cytometry (FACSCalibur, BD Biosciences, Franklin Lakes, NJ, USA). The experiment was repeated three times.

Statistical analysis. Data were analyzed using SPSS 21.0 (IBM SPSS, Armonk, NY, USA) statistical software. Measurement data are expressed as the mean \pm standard deviation. Comparisons between two groups were analyzed using an Independent-Samples t-test, whereas comparisons among multiple groups were analyzed using one-way analysis of variance. $\mathrm{P}<0.05$ was considered to indicate a statistically significant difference.

\section{Results}

$A D$ mice have poorer learning and memory abilities than normal mice. A behavioral assessment was performed to examine the learning and memory abilities of $\mathrm{AD}$ mice and the results were as follows (Table III): Compared with the normal mice, with respect to learning ability, reaction time in the $\mathrm{AD}$ mice was substantially longer and error times were significantly increased $(\mathrm{P}<0.05)$. With respect to memory ability, the reaction time of the $\mathrm{AD}$ mice was markedly shorter and error times were significantly longer $(\mathrm{P}<0.05)$. These results indicated that the 

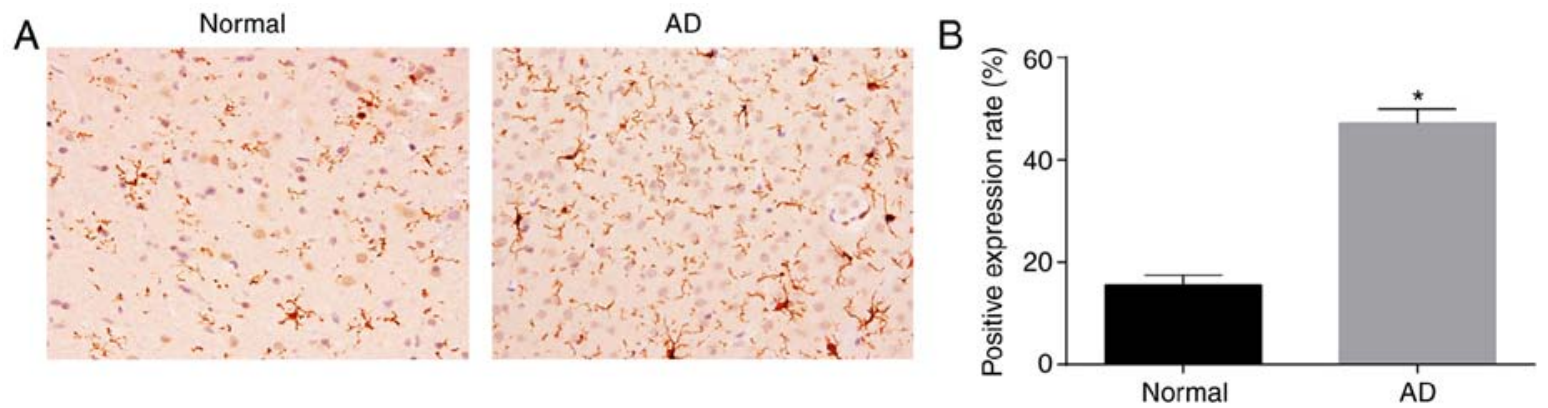

Figure 2. AD mice exhibit increased protein levels of HEY2 in the CA1 region of brain tissues. (A) Immunohistochemistry staining results of HEY2 protein (original magnification, x200). (B) Positive expression rate of HEY2 protein; "P<0.05, vs. normal group; HEY2, hairy and enhancer of split-related with YRPW motif protein 2; AD, Alzheimer's disease.
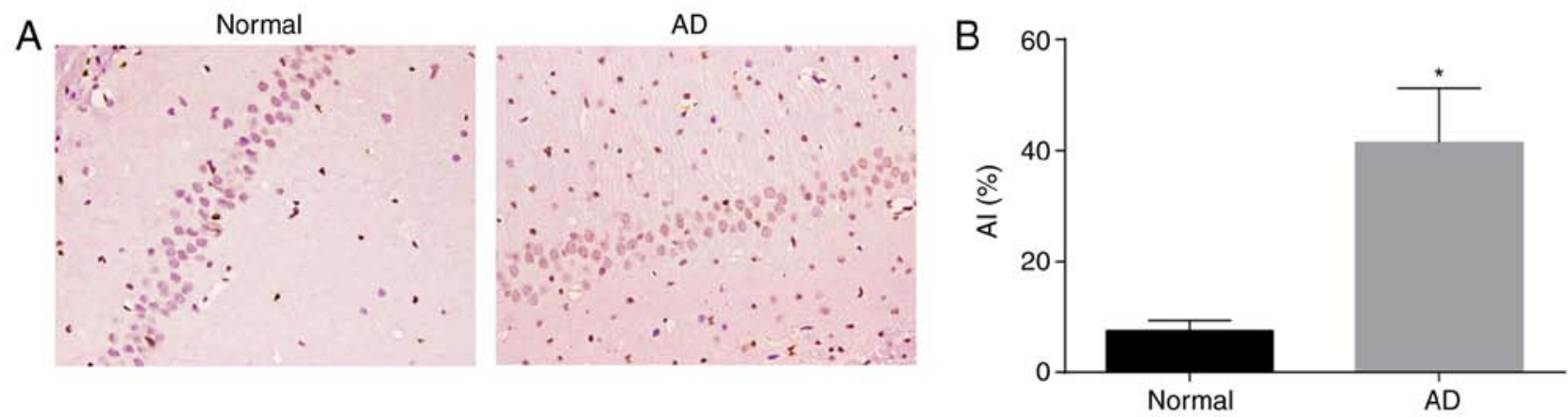

Figure 3. AD mice have higher neuronal apoptosis in the CA1 region of brain tissues. (A) Terminal deoxynucleotidyl transferase dUTP nick end labeling results of neuronal apoptosis (original magnification, $\mathrm{x} 400$ ); (B) AI results; " $\mathrm{P}<0.05$, vs. normal group. AD, Alzheimer's disease; AI, apoptotic index.
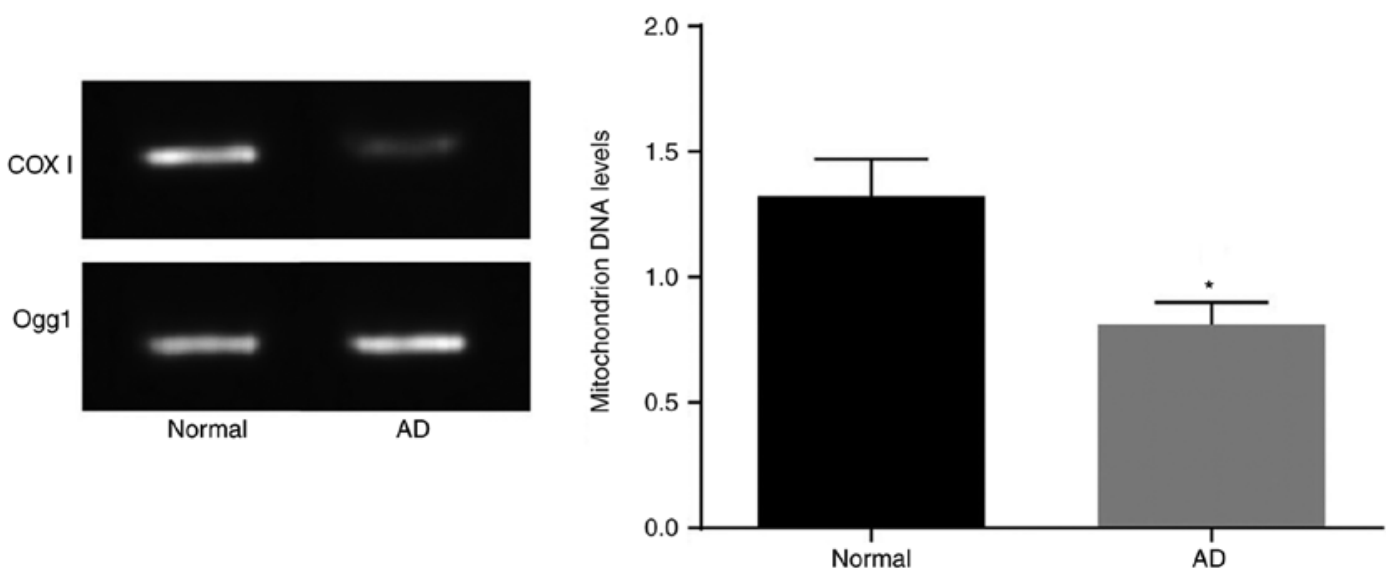

Figure 4. AD mice show decreased mitochondrial DNA levels. "P<0.05, vs. normal group. AD, Alzheimer's disease.

learning and memory abilities of the AD mice were substantially poorer than those of the normal mice.

AD mice have poorer oxidative stress function than normal mice. Oxidative stress markers were measured in the AD mice. The results of changes in oxidative stress functions are presented in Table IV. Compared with the normal mice, the activities of SOD and AChE were higher in the AD mice, whereas the activities of GSH-Px, GSH, MDA and $\mathrm{Na}^{+}-\mathrm{K}^{+}$-ATP were lower (all $\mathrm{P}<0.05$ ). These results indicated that, compared with the normal mice, the antioxidant capacity of the AD mice was substantially lower.
Pyramidal cells in the hippocampal CA1 region exhibit deteriorative morphological changes. Morphological changes of the pyramidal cells in the hippocampal CA1 region were measured with H\&E staining (Fig. 1). The normal formation of the hippocampus exhibited four clear layers of pyramidal cells with uniform morphology in CA1 region. Its fiber structure was clearly discernible without lymphocytic infiltration. The number of pyramidal cells in the AD mice was substantially reduced. The cell arrangement was disordered, and the layer was obscure with substantial lymphocytic infiltration. Pyramidal cells were markedly impaired, accompanied by karyopyknosis. Fiber structure was disordered and obscure, 


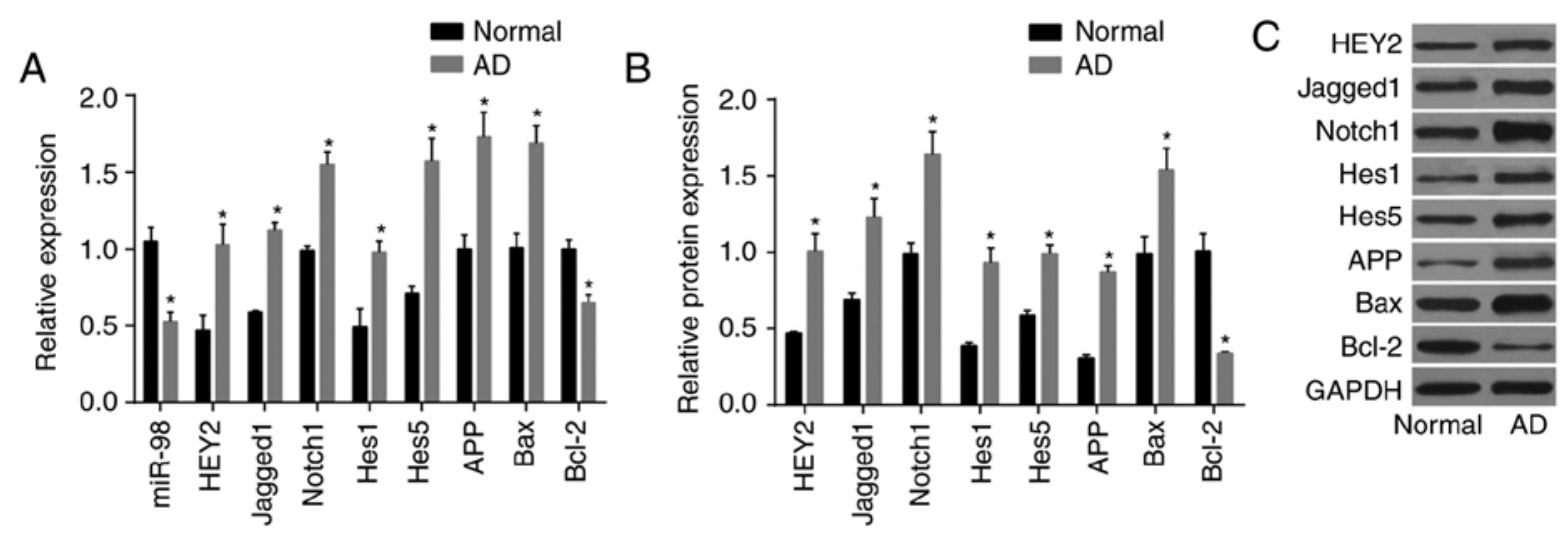

Figure 5. AD mice exhibit decreased levels of miR-98, increased mRNA and protein levels of HEY2, Jagged1, Notch1, Hes1, Hes5, APP, Bax, and reduced mRNA and protein levels of Bcl-2 in brain tissue. (A) Levels of miR-98 and mRNA levels of HEY2, Jagged1, Notch1, Hes1, Hes5, APP, Bax and Bcl-2, measured by reverse transcription-quantitative polymerase chain reaction analysis. (B) protein levels of HEY2, Jagged1, Notch1, Hes1, Hes5, APP, Bax and Bcl-2 measured by western blot analysis. (C) Western blot bands of HEY2, Jagged1, Notch1, Hes1, Hes5, APP, Bax and Bcl-2 proteins; "P<0.05, vs. normal group. AD, Alzheimer's disease; miR-98, microRNA-98; HEY2, hairy and enhancer of split-related with YRPW motif protein 2; Hes1, hairy and enhancer of split 1; Hes5, hairy and enhancer of split 5; APP, amyloid precursor protein; Bcl-2, B cell lymphoma 2; BAX, Bcl-2-associated X protein; GAPDH, glyceraldehyde-3-phosphate dehydrogenase.

and vacuolization was observed in the cytoplasm. These results demonstrated that the morphological changes of pyramidal cells in the hippocampal CA1 region showed deterioration in the AD mice, compared with those in the controls.

$A D$ mice have higher protein levels of HEY2 in the CAI region of brain tissues than normal mice. The protein expression of HEY2 in the CA1 region of brain tissues was measured by immunohistochemistry (Fig. 2A and B). HEY2 protein was mainly expressed in the cytoplasm and appeared brown-yellow. Compared with the AD mice, the number of brown-yellow positive grains in the brain tissues of normal mice was substantially lower. Compared with the normal mice, the positive rate of HEY2 protein in the brain tissues of $\mathrm{AD}$ mice was higher $(\mathrm{P}<0.05)$. These findings signified that the AD mice exhibited increased protein levels of HEY2 in the CA1 region of brain tissues.

$A D$ mice have higher $A I$ in the $C A 1$ region of brain tissues compared with normal mice. TUNEL staining was used to determine $\mathrm{AI}$ in the $\mathrm{CA} 1$ region of brain tissues of $\mathrm{AD}$ mice (Fig. 3A and B). Nuclear markers of positive cells appeared brown-yellow. The apoptosis of positive granulosa cells was lower in the brain tissues of normal mice and was substantially higher in the brain tissues of AD mice. Compared with the normal mice, the AD mice exhibited a higher level of neuronal apoptosis and $\mathrm{AI}$ in the $\mathrm{CA} 1$ region of brain tissues $(\mathrm{P}<0.05)$. These findings demonstrated that the AD mice had elevated $\mathrm{AI}$ in the $\mathrm{CA} 1$ region of brain tissues.

$A D$ mice have reduced mtDNA levels and dysfunctional neuronal mitochondria. The mtDNA levels were measured by PCR analysis (Fig. 4). Compared with those in the normal mice, neuron mtDNA levels in the brain tissues of the AD mice were lower $(\mathrm{P}<0.05)$. This suggested that $\mathrm{AD}$ mice had dysfunction of neuronal mitochondria.

$A D$ mice exhibit downregulated levels of miR-98, elevated HEY2 and activated notch-HEY2 signaling pathway.

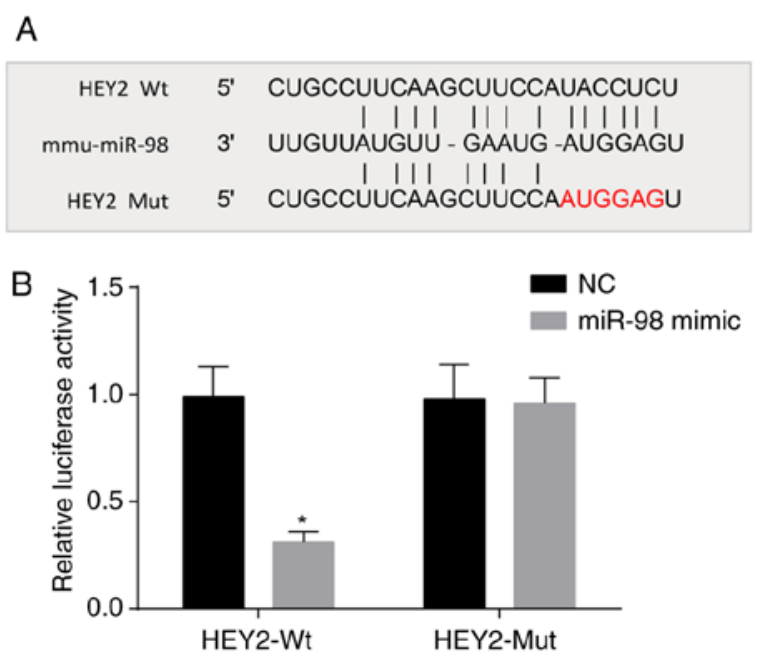

Figure 6. miR-98 targets HEY2. (A) Predicted binding site and corresponding mutation site of miR-98 and HEY2 3'UTR. (B) Relative luciferase activity detection. ${ }^{*} \mathrm{P}<0.05$, vs. NC group. miR-98, microRNA-98; HEY2, hairy and enhancer of split-related with YRPW motif protein 2; NC, negative control; Wt, wild-type; Mut, mutant.

RT-qPCR and western blot analyses were used to determine levels of miR-98 and mRNA and protein levels of HEY2, Jagged1, Notch1, Hes1, Hes5, APP, Bax and Bcl-2 in the brain tissues of AD mice (Fig. 5A-C). The brain tissues of the AD mice had decreased expression of miR-98, increased mRNA and protein levels of HEY2, Jagged1, Notch1, Hes1, Hes5, APP and Bax, and reduced mRNA and protein levels of Bcl-2 $(\mathrm{P}<0.05)$. These results suggested that, compared with the normal group, the $\mathrm{AD}$ group had lower levels of miR-98, higher levels of HEY2 and increased activation of the Notch-HEY2 signaling pathway.

miR-98 targets HEY2. According to the online analysis software, miR-98 and HEY2 3'UTR had a binding site (Fig. 6A). The results of the dual-luciferase reporter assay are shown in Fig. 6B. Compared with the $\mathrm{NC}$ group, the luciferase activity 

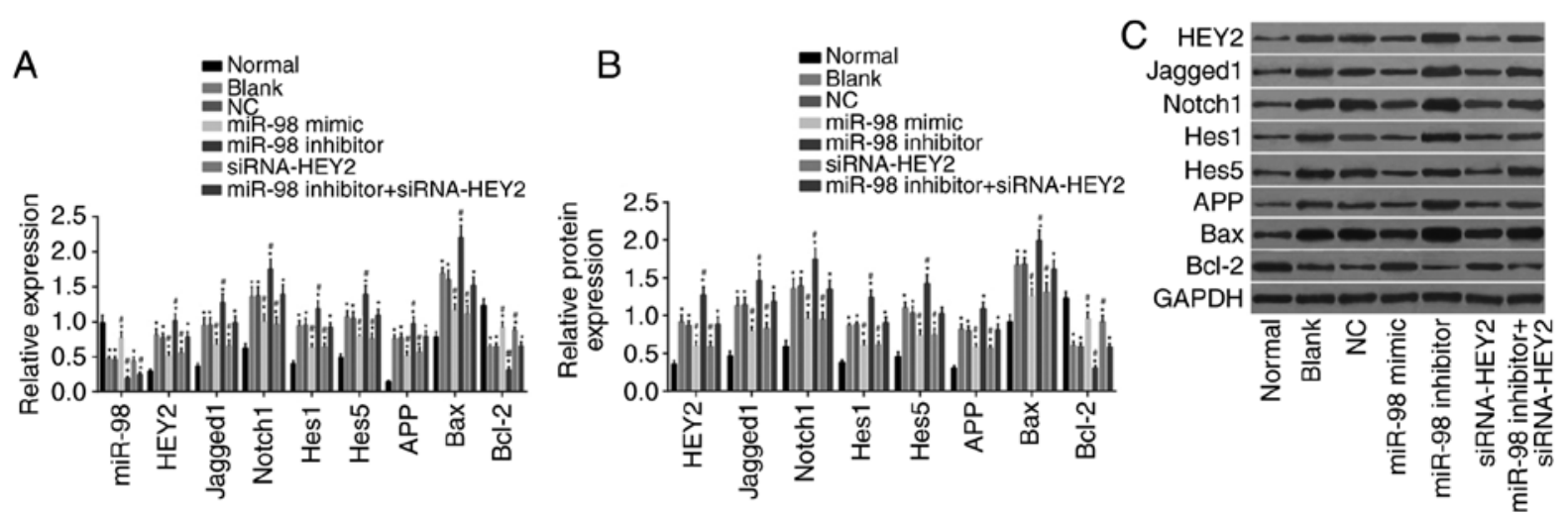

Figure 7. miR-98 contributes to inhibited HEY2 levels and inactivation of the Notch signaling pathway. (A) Levels of miR-98 and mRNA levels of HEY2, Jagged1, Notch1, Hes1, Hes5, APP, Bax and Bcl-2 in transfected hippocampal neurons among each group. (B) Protein levels of HEY2, Jagged1, Notch1, Hes1, Hes5, APP, Bax and Bcl-2 in transfected hippocampal neurons among each group. (C) Western blot images of HEY2, Jagged1, Notch1, Hes1, Hes5, APP, Bax and Bcl-2 proteins in transfected hippocampal neurons; ${ }^{*} \mathrm{P}<0.05$, vs. normal group; ${ }^{\sharp} \mathrm{P}<0.05$, vs. blank and NC groups. miR-98, microRNA-98; HEY2, hairy and enhancer of split-related with YRPW motif protein 2; Hes1, hairy and enhancer of split 1; Hes5, hairy and enhancer of split 5; APP, amyloid precursor protein; Bcl-2, B cell lymphoma 2; BAX, Bcl-2-associated X protein; GAPDH, glyceraldehyde-3-phosphate dehydrogenase; siRNA, small interfering RNA.

of the Wt-miR-98/HEY2 cotransfection group was decreased $(\mathrm{P}<0.05)$. However, no significant difference was observed in the luciferase activity of the Mut-miR-98/HEY2 plasmid group $(\mathrm{P}<0.05)$. Therefore, HEY2 was a target gene of miR-98.

miR-98 inhibits HEY2 and inactivates the Notch signaling pathway. RT-qPCR and western blot analyses were performed to determine miR-98 levels and the mRNA and protein levels of HEY2, Jagged1, Notch1, Hes1, Hes5, APP, Bax and Bcl-2 in neurons (Fig. 7A-C). Compared with the normal group, the other groups showed decreased levels of miR-98, increased mRNA and protein levels of HEY2, Jagged1, Notch1, Hes1, Hes5, APP and Bax, and reduced mRNA and protein levels of Bcl-2 (all $\mathrm{P}<0.05$ ). Compared with the blank and $\mathrm{NC}$ groups, the miR-98 mimic group exhibited elevated levels of miR-98, lower mRNA and protein levels of HEY2, Jagged1, Notch1, Hes1, Hes5, APP and Bax, and increased mRNA and protein levels of Bcl-2 (all $\mathrm{P}<0.05$ ). The miR-98 inhibitor group had decreased levels of miR-98, increased mRNA and protein levels of HEY2, Jagged1, Notch1, Hes1, Hes5, APP and Bax, and reduced mRNA and protein levels of Bcl-2 (all $\mathrm{P}<0.05$ ). The miR-98 inhibitor + si-HEY2 group had reduced levels of miR-98 $(\mathrm{P}<0.05)$, however, no significant change was found in the expression of the other genes $(\mathrm{P}>0.05)$. These results indicated that miR-98 contributed to the inhibited expression of HEY2 and suppressed the Notch signaling pathway.

miR-98 promotes and HEY2 inhibits viability in hippocampal neurons. Neuron viability was detected using an MTT assay (Fig. 8). The OD values of the hippocampal neurons in each group increased with time. Compared with the normal group, the proliferation rates of hippocampal neurons in the other groups were lower (all $\mathrm{P}<0.05)$. Compared with the blank and NC groups, the miR-98 mimic group and the siRNA-HEY2 group exhibited higher proliferation rates of hippocampal neurons, whereas the miR-98 inhibitor group exhibited lower proliferation rates of hippocampal neurons (all $\mathrm{P}<0.05$ ), with no significant change in the miR-98 inhibitor + siRNA-HEY2 group $(\mathrm{P}>0.05)$. These results suggested that miR-98 promoted

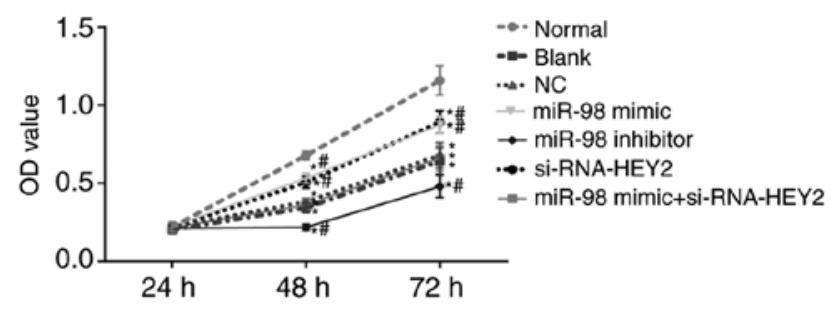

Figure 8. miR-98 enhances and HEY2 lowers viability in hippocampal neurons. ${ }^{*} \mathrm{P}<0.05$, vs. normal group; ${ }^{\#} \mathrm{P}<0.05$, vs. blank and NC groups. miR-98, microRNA-98; HEY2, hairy and enhancer of split-related with YRPW motif protein 2; siRNA, small interfering RNA; NC, negative control; OD, optical density.

hippocampal neuron viability whereas HEY2 inhibited the viability of hippocampal neurons.

miR-98 suppresses and HEY2 promotes apoptosis in hippocampal neurons. Hippocampal neuron apoptosis was detected by Annexin and V-FITC/PI double staining (Fig. 9A and B). Compared with the normal group, the apoptotic rates of hippocampal neurons in the other groups were higher (all $\mathrm{P}<0.05)$. Compared with the blank and NC groups, the miR-98 mimic group and the siRNA-HEY2 group exhibited lower apoptotic rates of hippocampal neurons, whereas the miR-98 inhibitor group exhibited a higher apoptotic rate (all $\mathrm{P}<0.05$ ), and no significant change was found in the miR-98 inhibitor + siRNA-HEY2 group $(\mathrm{P}>0.05)$. These results suggested that miR-98 inhibited apoptosis and HEY2 promoted apoptosis of hippocampal neurons.

\section{Discussion}

AD is characterized by neurofibrillary tangles, synaptic dysfunction and neurodegeneration; its incidence is increasing rapidly with the aging of the population as an increasing number of individuals approach the key risk period for this age-related disease $(26,27)$. Its characteristics include the loss of synapses and neuronal death, neurofibrillary tangles and extracellular $\mathrm{A} \beta$ plaques in the intracellular environment, all 

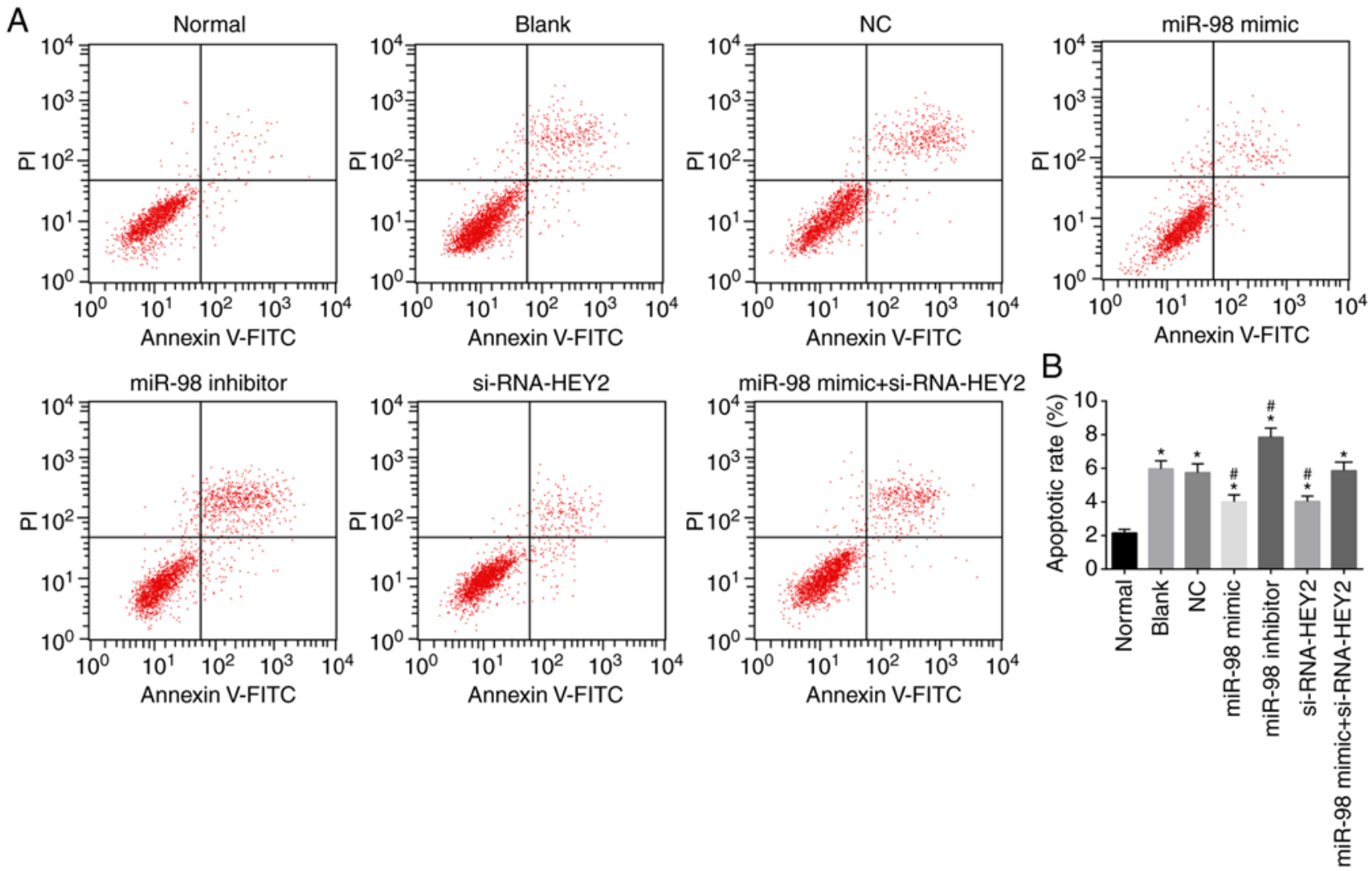

Figure 9. miR-98 inhibits and HEY2 improves apoptosis in hippocampal neurons. (A) Images of cell apoptosis in each group, detected by flow cytometry. (B) Apoptotic rates in each group; Annexin $\mathrm{V}(+) / \mathrm{PI}(-)$ represents early apoptotic cells; ${ }^{*} \mathrm{P}<0.05$, vs. normal group; ${ }^{*} \mathrm{P}<0.05$, vs. blank and $\mathrm{NC}$ groups. miR- 98 , microRNA-98; NC, negative control; HEY2, hairy and enhancer of split-related with YRPW motif protein 2; siRNA, small interfering RNA.

leading to cognitive decline (28). The present study investigated the effect of miR-98 on the production of $A \beta$, oxidative stress and mitochondrial dysfunction by targeting HEY2 and the Notch signaling pathway in AD mice.

The initial results demonstrated that $\mathrm{AD}$ mice had poorer learning and memory abilities, and lower antioxidant capacity, compared with the normal mice. Epidemiological and clinical investigations have demonstrated a role for reactive nitrogen species and ROS, known collectively as oxidative stress (29). It is considered to be one of the most important factors in the pathogenesis of AD (30). Certain antioxidants protect DNA from oxidative damage (31). Consequently, the weak antioxidant capacity of dementia mice may result in oxidative stress. In the present study, the mtDNA levels of AD mice were lower, suggesting that neuronal mitochondria were dysfunctional. Mitochondrial dysfunction is central to multiple diseases involving oxidative stress (32). Changes in mtDNA levels, usually measured as the mitochondrial genome to nuclear genome ratio and the mtDNA content in body tissues and fluids, is considered a biomarker of mitochondrial dysfunction (32).

The data obtained in the present study also indicated that, compared with the normal group, the expression of miR-98 was lower and the expression of HEY2 was higher in the AD group. The Notch-HEY2 pathway was activated. miR has emerged as a key post-transcriptional regulator of gene expression (33), regulating several normal cellular activities, including growth, differentiation, apoptosis, inflammation and tissue turnover (34). miR-98-5p has been reported to exhibit significantly different expression in patients with AD (35). A previous study demonstrated that miR-98-5p regulated the expression of SNX6 and was important in the accumulation of $\mathrm{A} \beta$ (36). miR-98 is also reported to induce an $\mathrm{AD}$-like disturbance by targeting insulin-like growth factor 1 and the overexpression of miR-98-promoted the production of $A \beta$, suggesting that miR-98 is vital in the development of the pathology of AD (37). Liu et al found that miR-98 was upregulated in rabbit brains during the progression of AD-like pathology, consistent with previous reports that miR-98 was upregulated in AD mouse models (38). Furthermore, during zebrafish arteriovenous differentiation, Sox 18 and Sox7 induced HEY2 ortholog gridlock, and a high expression of HEY2 has been found in other diseases, indicating that HEY2 may inhibit cell differentiation (21). However, miR-98 contributed to inhibition of the expression of HEY 2 and the Notch signaling pathway in the present study. In the miR-98 inhibitor group, the expression of miR-98 was lower and the expression levels of HEY2, Jagged1, Notch1, Hes1, Hes5, APP and Bax were higher, whereas the expression of $\mathrm{Bcl}-2$ was lower. Jagged1 is a Notch ligand; the targeted loss of this expression was shown to be sufficient to cause spatial memory loss and a reduction in the activation of exploration-dependent Notch (39). The Notch1 pathway is a cellular cascade with basic roles from brain development to adult brain function; the overactivation of Notch1 following brain injury is detrimental for neuronal survival (40). Hes1 and Hes5, fundamental helix-loop-helix factors, repress the expression of pro-neural factors, including Achaete-scute homolog 1, thus maintaining neural progenitor cells and inhibiting neuronal differentiation (41). APP has 
been investigated extensively for its role as a precursor of $\mathrm{A} \beta$ in $\mathrm{AD}$; it is potentially involved in the development of neural stem cells, in addition to the survival, outgrowth and repair of neurons (42). A previous study indicated that the increased expression of Bax enhanced apoptosis, whereas the overexpression of Bcl-2 inhibited apoptosis (43).

miR-98 promoted the growth of hippocampal neurons, whereas HEY2 inhibited the viability of the neurons. The hippocampus is involved in segregating memories, an ability that allows for cognitive flexibility and uses the neural process of pattern separation (44). Furthermore, miR-98 inhibited cell apoptosis, whereas HEY2 promoted the apoptosis of hippocampal neurons. A previous study indicated that miR-98 inhibited interleukin-1 $\beta$-induced cell apoptosis by regulating the expression of Bcl-2 (45).

Current treatment options for AD are limited to medications that decrease symptoms of dementia. Considering the rapidly aging population in the majority of regions of the world, novel therapeutic interventions for AD are urgently required (46). Therefore, the findings of the present study provide a rationale for the hypothesis that miR-98 targeting HEY2 inhibits the activity of Notch pathway, contributing to the inhibition of the production of $A \beta$ and to the improvement of oxidative stress and mitochondrial dysfunction in AD mice. However, additional investigations are required to further demonstrate the effects of miR-98 in the regulation of AD mice by targeting HEY2 through the Notch signaling pathway prior to its consideration as an applicable therapy for AD.

\section{Acknowledgements}

Not applicable.

\section{Funding}

No funding was received.

\section{Availability of data and materials}

The datasets used and/or analyzed during the current study are available from the corresponding author on reasonable request.

\section{Authors' contributions}

FZC, YZ and HZC wrote the manuscript, and conceived and designed the experiments. FZC and $\mathrm{YZ}$ analyzed the data. FZC and HZC collected and provided the samples for the study. All authors read and approved the final manuscript.

\section{Ethics approval and consent to participate}

The protocols of the present study were approved by the Institutional Review Board of the Affiliated Hospital of Taishan Medical University (Taishan, China). All animal experiments were performed according to the Guide for the Care and Use of Laboratory Animal by International Committees.

\section{Patient consent for publication}

Not applicable.

\section{Competing interests}

The authors declare that they have no competing interests.

\section{References}

1. Wenk GL: Neuropathologic changes in Alzheimer's disease. J Clin Psychiatry 64 (Suppl 9): S7-S10, 2003.

2. Scheltens P, Blennow K, Breteler MM, de Strooper B, Frisoni GB, Salloway S and Van der Flier WM: Alzheimer's disease. Lancet 388: 505-517, 2016.

3. Luque-Contreras D, Carvajal K, Toral-Rios D, Franco-Bocanegra D and Campos-Peña V: Oxidative stress and metabolic syndrome: Cause or consequence of Alzheimer's disease? Oxid Med Cell Longev 2014: 497802, 2014.

4. Chami L and Checler F: BACE1 is at the crossroad of a toxic vicious cycle involving cellular stress and $\beta$-amyloid production in Alzheimer's disease. Mol Neurodegener 7: 52, 2012.

5. Liggins C, Snyder HM, Silverberg N, Petanceska S, Refolo LM, Ryan L and Carrillo MC: International Alzheimer's Disease Research Portfolio (IADRP) aims to capture global Alzheimer's disease research funding. Alzheimers Dement 10: 405-408, 2014.

6. Yang Q, Wang T, Su N, Liu Y, Xiao S and Kapoula Z: Long latency and high variability in accuracy-speed of prosaccades in Alzheimer's disease at mild to moderate stage. Dement Geriatr Cogn Dis Extra 1: 318-329, 2011.

7. Sagy-Bross C, Kasianov K, Solomonov Y, Braiman A, Friedman A, Hadad N and Levy R: The role of cytosolic phospholipase A $2 \alpha$ in amyloid precursor protein induction by amyloid beta1-42: Implication for neurodegeneration. J Neurochem 132: 559-571, 2015.

8. Banote RK, Edling M, Eliassen F, Kettunen P, Zetterberg H and Abramsson A: $\beta$-Amyloid precursor protein-b is essential for Mauthner cell development in the zebrafish in a Notch-dependent manner. Dev Biol 413: 26-38, 2016.

9. Chen Y, Huang X, Zhang YW, Rockenstein E, Bu G, Golde TE, Masliah E and Xu H: Alzheimer's $\beta$-secretase (BACE1) regulates the cAMP/PKA/CREB pathway independently of $\beta$-amyloid. J Neurosci 32: 11390-11395, 2012.

10. Lu JX, Qiang W, Yau WM, Schwieters CD, Meredith SC and Tycko R: Molecular structure of $\beta$-amyloid fibrils in Alzheimer's disease brain tissue. Cell 154: 1257-1268, 2013.

11. Bao XQ, Li N, Wang T, Kong XC, Tai WJ, Sun H and Zhang D: FLZ alleviates the memory deficits in transgenic mouse model of Alzheimer's disease via decreasing beta-amyloid production and tau hyperphosphorylation. PLoS One 8: e78033, 2013.

12. Jiang Y,Zhou Z, Meng QT, Sun Q, Su W, Lei S, Xia Z and Xia ZY: Ginsenoside Rb1 treatment attenuates pulmonary inflammatory cytokine release and tissue injury following intestinal ischemia reperfusion injury in mice. Oxid Med Cell Longev 2015: 843721, 2015.

13. Simonian NA and Coyle JT: Oxidative stress in neurodegenerative diseases. Annu Rev Pharmacol Toxicol 36: 83-106, 1996.

14. Muhammad S, Bierhaus A and Schwaninger M: Reactive oxygen species in diabetes-induced vascular damage, stroke, and Alzheimer's disease. J Alzheimers Dis 16: 775-785, 2009.

15. Shen GX: Mitochondrial dysfunction, oxidative stress and diabetic cardiovascular disorders. Cardiovasc Hematol Disord Drug Targets 12: 106-112, 2012.

16. Li X, Zhang $M$ and Zhou H: The morphological features and mitochondrial oxidative stress mechanism of the retinal neurons apoptosis in early diabetic rats. J Diabetes Res 2014: 678123, 2014.

17. Weir HJ, Murray TK, Kehoe PG, Love S, Verdin EM, O'Neill MJ, Lane JD and Balthasar N: CNS SIRT3 expression is altered by reactive oxygen species and in Alzheimer's disease. PLoS One 7: e48225, 2012.

18. Wang X, Wang W, Li L, Perry G, Lee HG and Zhu X: Oxidative stress and mitochondrial dysfunction in Alzheimer's disease. Biochim Biophys Acta 1842: 1240-1247, 2014.

19. Brunst KJ, Sanchez Guerra M, Gennings C, Hacker M, Jara C, Bosquet Enlow M, Wright RO, Baccarelli A and Wright RJ: Maternal lifetime stress and prenatal psychological functioning are associated with decreased placental mitochondrial DNA copy number in the PRISM study. Am J Epidemiol 186: 1227-1236, 2017.

20. Hayashi Y, Haneji N, Hamano H and Yanagi K: Transfer of Sjogren's syndrome-like autoimmune lesions into SCID mice and prevention of lesions by anti-CD4 and anti-T cell receptor antibody treatment. Eur J Immunol 24: 2826-2831, 1994. 
21. Wu DC, Zhang MF, Su SG, Fang HY, Wang XH, He D, Xie YY and Liu XH: HEY2, a target of miR-137, indicates poor outcomes and promotes cell proliferation and migration in hepatocellular carcinoma. Oncotarget 7: 38052-38063, 2016.

22. Morioka T, Sakabe M, Ioka T, Iguchi T, Mizuta K, Hattammaru M, Sakai C, Itoh M, Sato GE, Hashimoto A, et al: An important role of endothelial hairy-related transcription factors in mouse vascular development. Genesis 52: 897-906, 2014.

23. Vidigal JA and Ventura A: The biological functions of miRNAs: Lessons from in vivo studies. Trends Cell Biol 25 137-147, 2015.

24. Siragam V, Rutnam ZJ, Yang W, Fang L, Luo L, Yang X, Li M, Deng Z, Qian J, Peng C and Yang BB: MicroRNA miR-98 inhibits tumor angiogenesis and invasion by targeting activin receptor-like kinase-4 and matrix metalloproteinase-11. Oncotarget 3: 1370-1385, 2012.

25. Livak KJ and Schmittgen TD: Analysis of relative gene expression data using real-time quantitative PCR and the 2(-Delta Delta C(T)) method. Methods 25: 402-408, 2001

26. Cummings J, Lee G, Mortsdorf T, Ritter A and Zhong K: Alzheimer's disease drug development pipeline: 2017. Alzheimers Dement (NY) 3: 367-384, 2017.

27. Sevigny J, Chiao P, Bussière T, Weinreb $\mathrm{PH}$, Williams L, Maier M, Dunstan R, Salloway S, Chen T, Ling Y, et al: Addendum: The antibody aducanumab reduces $\mathrm{A} \beta$ plaques in Alzheimer's disease. Nature 546: 564, 2017.

28. Kocahan S and Doğan Z: Mechanisms of Alzheimer's disease pathogenesis and prevention: The brain, neural pathology, $\mathrm{N}$-methyl-D-aspartate receptors, tau protein and other risk factors. Clin Psychopharmacol Neurosci 15: 1-8, 2017.

29. Saed GM, Diamond MP and Fletcher NM: Updates of the role of oxidative stress in the pathogenesis of ovarian cancer. Gynecol Oncol 145: 595-602, 2017.

30. Yang EJ, Ahn S, Ryu J, Choi MS, Choi S, Chong YH, Hyun JW, Chang MJ and Kim HS: Phloroglucinol attenuates the cognitive deficits of the 5XFAD mouse model of Alzheimer's disease. PLoS One 10: e0135686, 2015.

31. Moslemnezhad A, Mahjoub S and Moghadasi M: Altered plasma marker of oxidative DNA damage and total antioxidant capacity in patients with Alzheimer's disease. Caspian J Intern Med 7: 88-92, 2016.

32. Malik AN and Czajka A: Is mitochondrial DNA content a potential biomarker of mitochondrial dysfunction? Mitochondrion 13 481-492, 2013

33. Banerjee A and Luettich K: MicroRNAs as potential biomarkers of smoking-related diseases. Biomark Med 6: 671-684, 2012.

34. Panda H, Chuang TD, Luo X and Chegini N: Endometrial miR-181a and miR-98 expression is altered during transition from normal into cancerous state and target PGR, PGRMC1, CYP19A1, DDX3X, and TIMP3. J Clin Endocrinol Metab 97: E1316-E1326, 2012
35. Tan L, Yu JT, Tan MS, Liu QY, Wang HF, Zhang W, Jiang T and Tan L: Genome-wide serum microRNA expression profiling identifies serum biomarkers for Alzheimer's disease. J Alzheimers Dis 40: 1017-1027, 2014.

36. Li Q, Li X, Wang L, Zhang Y and Chen L: miR-98-5p acts as a target for Alzheimer's disease by regulating $\mathrm{A} \beta$ production through modulating SNX6 expression. J Mol Neurosci 60: 413-420, 2016.

37. Hu YK, Wang X, Li L, Du YH, Ye HT and Li CY: MicroRNA-98 induces an Alzheimer's disease-like disturbance by targeting insulin-like growth factor 1. Neurosci Bull 29: 745-751, 2013

38. Liu QY, Chang MN, Lei JX, Koukiekolo R, Smith B, Zhang D and Ghribi O: Identification of microRNAs involved in Alzheimer's progression using a rabbit model of the disease. Am J Neurodegener Dis 3: 33-44, 2014.

39. Marathe S, Jaquet M, Annoni JM and Alberi L: Jagged 1 is altered in Alzheimer's disease and regulates spatial memory processing. Front Cell Neurosci 11: 220, 2017.

40. Brai E, Alina Raio N and Alberi L: Notch1 hallmarks fibrillary depositions in sporadic Alzheimer's disease. Acta Neuropathol Commun 4: 64, 2016.

41. Kageyama R, Shimojo H and Imayoshi I: Dynamic expression and roles of Hes factors in neural development. Cell Tissue Res 359: 125-133, 2015

42. Dawkins E and Small DH: Insights into the physiological function of the $\beta$-amyloid precursor protein: Beyond Alzheimer's disease. J Neurochem 129: 756-769, 2014.

43. MacGibbon GA, Lawlor PA, Sirimanne ES, Walton MR, Connor B, Young D, Williams C, Gluckman P, Faull RL, Hughes $\mathrm{P}$ and Dragunow M: Bax expression in mammalian neurons undergoing apoptosis, and in Alzheimer's disease hippocampus. Brain Res 750: 223-234, 1997.

44. Burghardt NS, Park EH, Hen R and Fenton AA: Adult-born hippocampal neurons promote cognitive flexibility in mice. Hippocampus 22: 1795-1808, 2012.

45. Wang J, Chen L, Jin S, Lin J, Zheng H, Zhang H, Fan H, $\mathrm{He} \mathrm{F}, \mathrm{Ma} \mathrm{S}$ and Li Q: Altered expression of microRNA-98 in IL-1 $\beta$-induced cartilage degradation and its role in chondrocyte apoptosis. Mol Med Rep 16: 3208-3216, 2017.

46. Lannfelt L, Relkin NR and Siemers ER: Amyloid- $\beta$-directed immunotherapy for Alzheimer's disease. J Intern Med 275 284-295, 2014.

This work is licensed under a Creative Commons Attribution-NonCommercial-NoDerivatives 4.0 International (CC BY-NC-ND 4.0) License. 